\title{
Gestão da informação e do conhecimento e teoria da complexidade no contexto empresarial: um estudo no setor de comunicação e tecnologia
}

\section{Beatriz Rosa Pinheiro dos Santos}

Universidade Estadual Paulista "Julio de Mesquita Filho".

Faculdade de Filosofia e Ciências (UNESP/FFC), Brasil

pinheiro.santos@unesp.br

\section{Erick Pacheli Pereira}

Universidade Estadual Paulista. Faculdade de Filosofia e Ciências

(UNESP/FFC), Brasil

erick@revelare.com.br

\section{Ieda Pelógia Martins Damian}

Universidade Estadual Paulista. Faculdade de Filosofia e Ciências (UNESP/FFC); Universidade de São Paulo. Faculdade de Filosofia, Ciências e Letras de Ribeirão Preto (USP/FFCLRP), Brasil iedapm@usp.br

Cita sugerida: Santos, B. R. P., Pereira, E. P. y Damian, I. P. M. (2018). Gestão da informação e do conhecimento e teoria da complexidade no contexto empresarial: um estudo no setor de comunicação e tecnologia. Palabra Clave (La Plata), 8(1), e060. https://doi.org/10.24215/18539912e060

Recibido: 7 de febrero de 2018 - Aceptado: 18 de junio de 2018 - Publicado: 31 de octubre de 2018

(c) (1) (2) Esta obra está bajo licencia Creative Commons Atribución-NoComercial-CompartirIgual 4.0 Internacional cc) 


\title{
Gestão da informação e do conhecimento e teoria da complexidade no contexto empresarial: um estudo no setor de comunicação e tecnologia
}

\author{
Information and knowledge management and complexity theory in the business context: a study in the \\ communication and technology sector
}

Beatriz Rosa Pinheiro dos Santos

Universidade Estadual Paulista "Julio de Mesquita Filho".

Faculdade de Filosofia e Ciências (UNESP/FFC), Brasil

pinheiro.santos@unesp.br

Erick Pacheli Pereira

Universidade Estadual Paulista. Faculdade de Filosofia e

Ciências (UNESP/FFC), Brasil

erick@revelare.com.br

Ieda Pelógia Martins Damian

Universidade Estadual Paulista. Faculdade de Filosofia

e Ciências (UNESP/FFC); Universidade de São Paulo.

Faculdade de Filosofia, Ciências e Letras de Ribeirão Preto

(USP/FFCLRP), Brasil

iedapm@usp.br

\section{Resumo:}

Uma sociedade imersa em grandes quantidades de informação deve ser pautada pela integração dos mais variados contextos organizacionais e informacionais, a fim de produzir conhecimento com características inter, multi, pluri e transdisciplinares. Assim, apresenta-se o seguinte problema de pesquisa: a empresa contemplada pela pesquisa, pertencente ao ramo de comunicação e tecnologia, possui uma cultura organizacional voltada à promoção e desenvolvimento da gestão da informação e do conhecimento baseada no pensamento complexo? O objetivo da pesquisa é verificar se esta empresa apresenta fatores que indicam uma cultura organizacional voltada à promoção e desenvolvimento da gestão da informação e do conhecimento em suas práticas de trabalho, com base na teoria da complexidade. Para isso, foi realizada uma pesquisa descritivo-exploratória de natureza qualitativa, utilizando como instrumento de pesquisa o roteiro de entrevista, e como método de análise, a "Análise de Conteúdo". Os resultados demonstram que o ambiente organizacional desenvolve de maneira mais acentuada as práticas de gestão da informação do que de gestão do conhecimento, baseando-se em alguns princípios do pensamento complexo desenvolvidos em paralelo com a gestão da informação, e se pode apontar que dos sete princípios do pensamento complexo, os desenvolvidos na empresa pesquisada são: princípio hologramático, princípio da auto-eco-organização, princípio do círculo retroativo e princípio do círculo recursivo.

PalaVras-ChaVE: Gestão da informação, Gestão do conhecimento, Teoria da complexidade, Pensamento complexo.

\section{Abstract:}

A society immersed in large amounts of information must be guided by the integration of the most varied organizational and informational contexts, in order to produce knowledge with inter, multi, multi and transdisciplinary characteristics. Thus, the following research problem is presented: Does the company contemplated by the research, belonging to the field of communication and technology, have an organizational culture focused on the promotion and development of information and knowledge management based on complex thinking? The objective of the research is to verify if this company presents factors that indicate an organizational culture focused on the promotion and development of information and knowledge management in its work practices, based on complexity theory. For this, a descriptive-exploratory research of a qualitative nature was carried out, using as a research tool the interview script, and as a method of analysis, the 'Content Analysis'. The results show that the organizational environment develops more strongly the practices of information management than of management of knowledge, based on some principles of complex thinking developed in parallel with the information management, and it can be pointed out that of the seven 
principles of complex thinking, those developed in the researched enterprise are: hologramatic principle, self-eco-organization principle, retroactive circle principle and recursive circle principle.

KEYWORDS: Information management, Knowledge management, Theory of complexity, Complex thinking.

\section{INTRODUÇÃo}

A sociedade da Informação é compreendida como aquela que está alicerçada pela informação, pelo conhecimento e pelas tecnologias de informação e comunicação (TIC), e as organizações podem ser compreendidas como entidades e agentes orgânicos desta sociedade (Valentim, 2007). Para a autora, essas organizações influenciam o ambiente em que se encontram inseridas, bem como também são influenciadas por ele.

Atualmente, as pessoas estão vivendo num contexto onde a informação segue produzida e compartilhada em grandes quantidades e de forma fragmentada, o que acaba gerando, na maioria das vezes, uma produção incontrolada de conhecimento não eficaz. À vista disso, Morin (2005) afirma que esta sociedade está sendo cada vez mais ameaçada de maneira grave, devido a esse desenvolvimento incontrolado do conhecimento.

Assim, como parte ativa desse contexto, as empresas necessitam progredir quanto à aplicação da gestão da informação e do conhecimento em suas práticas de trabalho, orientadas por uma visão sistêmica de gestão e auto-organização a fim de criar ambientes revolucionários e inovadores, e, concomitantemente, sustentar a complexidade que contribui para o desenvolvimento da atual sociedade. Valentim (2007, p. 13) corrobora que "a Sociedade da Informação necessita urgentemente da compreensão de sua importância, por parte das organizações, pois somente elas podem modificar os valores e a cultura de um país”.

Ao mesmo passo, as organizaçóes precisam compreender e se conscientizarem de que gerenciar a complexidade do seu ambiente, por meio da visão sistêmica e interdisciplinar, é importante para o seu desenvolvimento e sobrevivência no mercado. E para tornar essa consciência em algo real e prático nos ambientes organizacionais indica-se a inserção da gestão da informação e do conhecimento em suas práticas de trabalho.

A Gestão do Conhecimento (GC) está diretamente ligada ao conhecimento tácito, que se encontra na mente dos indivíduos e é considerada por Valentim (2004) uma ferramenta de suma importância para atualidade, pois se apropria de um montante de estratégias voltadas a criar, adquirir, compartilhar e utilizar o conhecimento nas tomadas de decisão.

Este conhecimento é originário dos próprios seres humanos, diante da informação que internalizam, do aprendizado e dê suas experiências de vida, portanto, quando as pessoas se socializam, a probalidade de surgir mais conhecimentos é muito alta, o que pode ser considerado um resultado muito positivo para o universo organizacional. Além do mais, essa interação faz parte da complexidade como também da visão sistêmica que a mesma carrega consigo.

Quanto a Gestão da Informação (GI), Madsen (2013) ressalta que, assim como a Ciência da Informação, também possui abordagens interdisciplinares, que são necessárias para a efetividade dos resultados abarcados pela execução de suas atividades. Segundo Valentim (2004), a GI trabalha em locais que contenham informação registrada, em suportes de papel e sistemas de informação, e está presente nos fluxos formais de informação. Para a autora, a gestão da informação é um conjunto de atividades responsáveis por identificar as necessidades informacionais, mapear, coletar, filtrar, analisar, organizar, armazenar e disseminar a informação, sempre com o propósito de apoiar as tomadas de decisão dos gestores e funcionários.

Por isso, essa gestão se configura atualmente como uma ferramenta estratégica e necessária, do ponto de vista econômico e social, que surge para mediar os processos informacionais na chamada sociedade da informação (Malin, 2012).

Portanto, não há dúvidas que tanto a GI como a GC podem ser consideradas processos e ferramentas relevantes para tornar práticos os fundamentos da teoria da complexidade no contexto das organizaçóes, 
incentivando a inter, multi, pluri e transdisciplinaridade, construindo um ambiente sistêmico e contribuindo para a consistência da sociedade atual.

O pensamento complexo se relaciona com a gestão da informação e do conhecimento, porque possui como intuito a valorização do ser humano, da informação e dos sistemas de informação, além de ser um pensamento que trabalha com a incerteza, e que é capaz de conceber a organização. É um pensamento capaz de reunir, contextualizar e globalizar, entretanto, ao mesmo tempo, reconhece o singular, o individual e o concreto (Morin, 2013).

Assim, a partir dessas reflexões, tem-se o seguinte problema de pesquisa: a empresa contemplada pela pesquisa, pertencente ao ramo de comunicação e tecnologia, possui uma cultura organizacional voltada à promoção e desenvolvimento da gestão da informação e do conhecimento baseada no pensamento complexo? Esse trabalho possui como objeto de pesquisa a cultura organizacional voltada à promoção da GI, GC e teoria da complexidade em um ambiente organizacional, e se justifica por inter-relacionar literaturas dos campos científicos da Ciência da Informação e da Administração.

O objetivo da pesquisa é verificar se esta empresa pesquisada apresenta fatores que indicam uma cultura organizacional voltada à promoção e ao desenvolvimento da gestão da informação e do conhecimento em suas práticas de trabalho, com base na teoria da complexidade. Para isso, foi realizada uma pesquisa descritivoexploratória de natureza qualitativa, e como método de análise optou-se por utilizar a "Análise de Conteúdo".

\section{GESTÃo DA INFORMAÇÃo}

A GI encontra-se envolvida por diversas abordagens e diferentes campos do conhecimento, pois a gestão da informação é visualizada pela ciência da computação como gestão de dados, o campo da administração como uma ferramenta de gestão dos sistemas de informação, como também da informação tácita e registrada, e a ciência da informação, que estuda a gestão da informação por diversas abordagens, especialmente pela inteligência competitiva e organizacional (Valentim, 2010).

De acordo com Martins (2014), a GI passou a ser uma área mais bem reconhecida devido à explosão documental após a $2^{\text {a }}$ Guerra Mundial, e também após o advento das TIC, que possibilitaram que a informação pudesse ser considerada um recurso importante de ser gerenciado.

Assim, a GI possui inúmeros conceitos, desenvolvidos por diversos autores. É desenvolvida por meio de processos, que, de acordo com McGee e Prusak (1994), são um conjunto de tarefas que devem estar conectadas entre si e com o ambiente em que estão inseridas. Nesse sentido, Choo (2003b) corrobora que a GI é considerada uma rede de processos que objetivam adquirir, criar, organizar, distribuir e usar a informação.

Silva e Tomaél (2007) acreditam que, mais do que gerenciar informação registrada, a GI compreendese em processos que analisam as pessoas envolvidas com a produção e utilização da informação, bem como os recursos usados por essas - como a tecnologia da informação, fontes, serviços e sistemas informacionais. Desse modo, de acordo com as autoras, a GI torna-se responsável por gerir não somente os recursos internos, mas também os externos.

Nesta linha de raciocínio, Ponjuán Dante (2007, p. 91) concorda que "as pessoas não são apenas as que projetam, mas são também as que manuseiam e utilizam os sistemas de informação". Para a autora, algumas operações relacionadas nos sistemas de informação podem ser efetuadas por máquinas, porém somente os seres humanos podem dar a verdadeira qualidade e diferenciais aos processos, visto que são os elementos mais importantes que existem na sociedade, que "têm a capacidade de criar e transformar o mundo" (Ponjuán Dante, 2007, p. 91).

Logo, segundo Ponjuán Dante (2007), a GI se configura em processos que utilizam os recursos econômicos, físicos, humanos e materiais para o gerenciamento e uso da informação nos diversos contextos organizacionais e da sociedade. 
Do ponto de vista de McGee e Prusak (1994), a GI está envolvida nas etapas básicas de identificação, coleta, tratamento, classificação, disseminação e uso da informação. Para os autores essas etapas são exclusivamente desenvolvidas com um cunho estratégico para tomada de decisão nos contextos empresariais.

Davenport (2002) também contribui para a existência dos diversos conceitos pertencentes à GI, estudando tal gestão sob os fundamentos da ecologia da informação, que se constitui em administrar a informação envolvida com os aspectos comportamentais do ser humano e da sua relação com o mundo informacional bruto.

A fim de proporcionar melhor compreensão sobre esses conceitos, foram escolhidos modelos de GI de alguns dos principais autores dessa temática, são eles: modelo de McGee e Prusak (1994), modelo de Davenport (1994), modelo de Choo (2003a), e modelo de Valentim (2004).

O modelo de GI de McGee e Prusak (1994) apresenta processos separados que, quando executados, se transformam em um gerenciamento efetivo de informações. Esses processos são denominados como: identificação de necessidades de informação; coleta/entrada de informação; classificação e armazenamento de informação; tratamento e apresentação da informação; desenvolvimento de produtos e serviços de informação; distribuição e disseminação da informação, e análise e uso da informação.

O modelo de Davenport (1994) possui características que propiciam valor à subjetividade do ser humano, e está separado nos seguintes processos: Determinação das exigências de informação; Obtenção de informações; Distribuição da informação, e Uso da informação.

O modelo de Choo (2003a) segue uma linha de raciocínio voltada à organização e valorização do conhecimento tácito dos funcionários, que adquirem esse conhecimento por meio da informação e, logo, da GI. Os processos desse modelo se dividem em: identificação das necessidades informacionais; aquisição da informação; organização e armazenamento da informação; desenvolvimento de produtos e serviços de informação; distribuição da informação; e uso da informação.

Por fim, Valentim (2004) desenvolveu um modelo baseado no que chama de atividades base da gestão da informação que se denominam: identificar demandas e necessidade de informação; mapear e reconhecer fluxos formais; desenvolver a cultura organizacional positiva em relação ao compartilhamento e socialização da informação; proporcionar a comunicação informacional de forma eficiente, utilizando tecnologias de informação e comunicação; prospectar e monitorar informações; coletar, selecionar e filtrar informações; tratar, analisar, organizar, armazenar informações, utilizando tecnologias de informação e comunicação; desenvolver sistemas corporativos de diferentes naturezas, visando o compartilhamento e uso da informação; elaborar produtos e serviços informacionais, e fixar normas e padrões de sistematização da informação.

Dessa maneira, muitas são as etapas relativas ao processo de gerir informações e, portanto, a tarefa de unir todas essas etapas torna-se imprescindível para inserção de uma GI baseada no pensamento complexo e na integração das partes. Ademais, o ato de desenvolver as etapas da GI também é considerado importante para a concretização da GC; afinal, informação é matéria-prima do conhecimento.

\section{GestÃo do CONHECIMENTO}

Nas organizações, a informação e o conhecimento tornam-se ferramentas relevantes, pois possuem o papel de amenizar ou reduzir a sensação de incerteza dos funcionários (Valentim, 2007). De acordo com a autora, o conhecimento é produzido pelos funcionários por meio da internalização de diferentes informações e de suas percepções pessoais.

Para Davenport e Prusak (1998, p. 6), o conhecimento é

uma mistura fluída de experiência condensada, valores, informação contextual e insight experimentado, a qual proporciona uma estrutura para a avaliação e incorporação de novas experiências e informações. Ele tem origem e é aplicado na mente dos conhecedores. Nas organizações, ele costuma estar embutido não só em documentos ou repositórios, mas também em rotinas, processos, práticas e normas organizacionais. 
De acordo com Valentim (2004, não paginado), a gestão do conhecimento é

um conjunto de estratégias para criar, adquirir, compartilhar e utilizar ativos de conhecimento, bem como estabelecer fluxos que garantam a informação necessária no tempo e formato adequados, a fim de auxiliar na geração de ideias, solução de problemas e tomada de decisão.

Segundo Cascão (2014), a GC é considerada uma nova área de estudos, que vem para auxiliar as mudanças do ambiente organizacional, porque promove a criação e o compartilhamento do conhecimento dos indivíduos que estão presentes nas organizações.

De acordo com Choo (2003b), esse tipo de gestão exige e proporciona: (a) adaptação dos funcionários às mudanças do ambiente organizacional; (b) aprendizagem constante, o que propicia uma mudança cultural; (c) utilização do conhecimento dos funcionários para a geração de inovação no ambiente organizacional, e (d) focalização do conhecimento nas tomadas de decisões efetivas.

Dessa maneira, pode-se afirmar que a gestão do conhecimento se constitui em um processo inovador, que se utilizado de modo adequado é capaz de proporcionar ganhos eficazes para uma organização.

Entretanto, Heisig et al. (2016) afirmam que a gestão da informação e a gestão do conhecimento são processos integrados e dependentes dos aspectos trabalhados na cultura organizacional de uma empresa, no sentido de que tanto a gestão da informação como a gestão do conhecimento necessitam de incentivos para de fato sucederem dentro do ambiente organizacional.

\section{Cultura Organizacional}

A cultura organizacional está atrelada a gestão da informação e do conhecimento, assim como está com a sociedade da informação, visto que se torna a base para promover ambas em um ambiente organizacional, bem como também inibir essa promoção.

Para Valle e Costa (2013), uma das maiores restrições relacionadas à gestão da informação e do conhecimento nas organizações está relacionada ao próprio fato de que os gestores das empresas não atribuem valor ao capital intelectual e ao conhecimento dos funcionários. À vista disso, a cultura organizacional é o grande cerne de ser trabalhado para que essa desvalorização não se estenda.

Para conceber o conceito de cultura organizacional é necessário antes de tudo entender o que o conceito de cultura compreende. De acordo com Mead et al. (2015), a cultura é um processo decorrente da diversidade humana, considerada um espaço que proporciona a criação, a critica, o conflito, a expressão, transgressão e liberdade pessoal e profissional da história de cada ser humano. Acrescenta-se a isso a definição inicial de Geertz (2013) da cultura como uma construção histórica que, partindo da lógica em rede, forma uma teia de significados.

De acordo com Schein (2009), cultura organizacional é um conjunto de pressupostos básicos aprendidos pelos funcionários, para resolução dos seus problemas organizacionais. $\mathrm{O}$ autor também revela que essa cultura opera como um espelho para os funcionários, no modo em que eles devem pensar, sentir e agir no ambiente da empresa. Mas sobre operações em rede, as interações entre os diferentes atores no seio da cultura organizacional devem necessariamente ser levadas em conta.

De acordo com Ronchi (2012), a cultura organizacional é um processo que deve estar sempre em construção, pois auxilia na moldagem do comportamento dos funcionários com relação à busca por qualidade no processo produtivo e a própria comunicação interpessoal com os demais colegas. Ainda de acordo com o autor, a cultura organizacional é tida como um conjunto de valores e pressupostos básicos, expressos na capacidade de ordenar, construir significados e identidade organizacional, bem como de agir como um elemento de comunicação entre os funcionários.

Com base nessas definições, afirma-se que a cultura organizacional reflete a personalidade de uma organização, seu modo de agir no ambiente externo e interno, suas politicas de contratação, o perfil dos 
seus stakeholders, seu cronograma de produção, suas maneiras de enfrentar a concorrência, suas práticas de marketing, suas maneiras de usar a informação e construir, socializar e usar o conhecimento. Dito de outra maneira, a cultura organizacional influência todas as práticas e fatores inerentes às organizações.

Todos esses elementos citados como constituintes da cultura organizacional podem ser consideradas variáveis que constantemente precisam ser transformadas, de acordo com as demandas advindas das mudanças que sofrem as sociedades, pois para Valentim (2007) as instituições tanto influenciam o meio em que estão inseridas, como recebem influência do meio.

Dessa maneira, considerando o fato de que a cultura organizacional pode ser a base para promoção do desenvolvimento da gestão da informação e do conhecimento nas organizações, cabe refletir a respeito da influência que esta pode exercer na adoção de uma consciência voltada ao pensamento complexo, integrado e interdisciplinar do ambiente organizacional como um todo.

\section{Teoria da Complexidade: o PENSAMENTo COMPleXo}

A complexidade surge como resposta alternativa ao modelo cartesiano de se construir a ciência moderna, que irradiou a partir do século XII e hoje domina os mais variados ambientes de vivência e atuação de pessoas, inclusive das organizações. Essa maneira cartesiana é o paradigma dominante, que objetiva separar e reduzir os conceitos e parâmetros científicos a fim de torná-los mais simples e limitá-los a aspectos mensuráveis, a fim de chegar ao consenso e manter distância de quaisquer dúvidas e questionamentos (Morin, 2007).

Trata-se da busca incessante em construir, por meio de abordagens fragmentadas e unidimensionais, uma verdade absoluta advinda de um pensamento linear que não valoriza a diversidade e a contradição, o que ocasiona um olhar desintegrado sobre tudo que está intimamente ligado, e resulta num olhar unificado sobre o que é diverso, mutilando, desta forma, detalhes que impedem compreensões ricas e aprofundadas sobre uma realidade (Morin, 2005).

A abordagem tradicional da ciência apresenta sinais de desgaste e insuficiência em dar conta de questões relacionadas aos fenômenos culturais ou que tenham relação com o sujeito. Isto porque ao se observar estas questóes sobre a ótica da racionalidade, automaticamente excluem-se as riquezas de um sujeito composto por dimensões humanas e subjetivas, renegam-se as particularidades do ser, que é descrito com base em determinismos e estereótipos. Esta compreensão resulta no tratamento do indivíduo em seus ambientes organizacionais, por meio de um processo mecânico, onde se podem controlar todas as variáveis de um indivíduo e estabelecer padrões de causa e efeito e conformidade, ferindo completamente sua humanidade.

Esta formatação do paradigma dominante pode ser identificada nos atos organizacionais cotidianos que tem a lógica econômica do lucro sobrescrevente ao valor do ser humano, reduzindo-o a um mero recurso. Este paradigma é evidenciado também pela relação entre sentimento de realização pessoal associado a cargos mais altos na hierarquia, assim como na deturpação da compreensão de progresso humano, definindo esta compreensão apenas como crescimento econômico progressista.

Trazendo um sentimento de esperança em equilibrar este cenário nocivo ao ser, o pensamento complexo aparece no final do século XX como um convite a reflexão e a tomada de consciência sobre a nocividade do então caminhar da humanidade, assim como também espera a construção de práticas que transformem este contexto por meio da exigência de um pensamento mais amplo a respeito dos fenômenos. Este pensamento não tem como objetivo eliminar os princípios da ordem, da separabilidade e da lógica, mas sim de integrá-los em uma concepção mais rica (Morin, 2013).

A complexidade busca uma ruptura do paradigma científico atual e se abre a novos conhecimentos por meio da religação dos saberes (Morin, 2007). Traz o indivíduo para o centro, reconhecendo o poder singular, e convida ao diálogo aspectos heterogêneos e contraditórios como a ordem e a desordem, compreendendo que estes são inseparáveis e não excludentes. Releva a incerteza, o acaso, e a ambiguidade das discussões; aborda 
aspectos invisíveis e se abre a uma compreensão multidimensional na busca pela compreensão da realidade em suas diferentes nuances (Morin, 2005).

Logo, o pensamento complexo é abrangente, não partidário, e se volta ao ser social e a solidariedade, buscando esclarecer o mundo por meio da interação entre o que já é conhecido e novas formas de compreender, agir, e encarar a sociedade e seus fenômenos. Propõe uma nova maneira de olhar o mundo e de vivê-lo.

A proposta integralizadora da complexidade faz um convite para a quebra de fronteiras disciplinares e para a transcendência destas disciplinas na construção de compreensões e novos conhecimentos para um fim comum: compreender fenômenos e realidades. Desta forma, cabe estabelecer interrelações entre a gestão da informação e do conhecimento pela ótica da teoria da complexidade nas organizações, já que, apartando-se de uma reflexão pautada apenas nos resultados empresariais medidos em lucro, tem-se o sujeito como um componente central nestas esferas.

Nas organizações, assim como em qualquer elemento resultante de toda a construção socio-histórica, os fenômenos comumente são abordados a partir do "paradigma da simplificação" (Morin, 2005), que tende a reduzi-los de forma a não valorizar a riqueza dos detalhes e contraposições. Desta forma, é essencial vislumbrar as abordagens organizacionais a partir de um pensamento complexo que "integra os modos simplificadores e abrange as multifaces que constituem o contexto" (Morin, 2005, p. 13).

A ausência de consciência organizacional a respeito da complexidade e a não introdução deste pensamento no cerne da organização - isto é, renegar a complexidade em suas políticas e diretrizes organizacionais que estabelecem a sua missão e determinam suas atividades cotidianas de planejamento e tomadas de decisões pode levar as organizações a ingressarem em um ciclo de "inteligência cega [que] destrói os conjuntos e as totalidades, isola todos os seus objetos do seu meio ambiente" (Morin, 2005, p. 12), que culmina em uma visão "mutiladora e unidimensional" (Morin, 2005, p. 13). Na prática, por exemplo, uma organização que tem a complexidade, a gestão da informação e do conhecimento longe da sua cultura organizacional pode estar trabalhando sob modelos de gestão em diversas áreas, seja na produção, no financeiro ou no marketing, de forma aparentemente correta e clarificada, onde é possível mensurar dados, informações e conhecimentos sobre as variáveis organizacionais. Porém, se estes dados, informações e conhecimentos não são observados e analisados de maneira integrada e multidimensional, as interpretações da realidade apresentadas pelos mesmos podem ser errôneas e resultar em tomadas de decisão equivocadas.

Por isso, o distanciamento das organizações do pensamento complexo, a desvalorização do ser humano como detentor do conhecimento e a desintegração dos setores e saberes acarretam desvantagens e afetam o crescimento de qualquer empresa.

A complexidade não surge na ânsia de ir à contramão do paradigma dominante, que é resultado da influência do sistema capitalista nas organizações, mas busca um modelo alternativo que possibilite a convivência com o modelo atual e a transformação constante na busca do desenvolvimento da complexidade em todos os contextos, seja no social, no político ou no organizacional.

Para que ocorra nas organizações a tomada de consciência em relação ao pensamento complexo - e que este pensamento atinja todos os departamentos a fim de causar efeito positivo - deve-se buscar por uma transformação que seja estabelecida nos conceitos e na construção socio-histórica das organizações. Pois, se as novas abordagens a serem estabelecidas nesses ambientes, no caso as abordagens do pensamento complexo e a inserção da gestão da informação e do conhecimento não forem enraizadas na cultura organizacional, as ações práticas do cotidiano das organizações irão sofrer resultados negativos. 


\section{INTER-RELAÇÕES ENTRE GESTÃo DA INFORMAÇÃO, GESTÃo DO CONHECIMENTO E PENSAMENTO COMPLEXO}

Seguindo a linha de pensamento complexo tal como definido na seção anterior, é possível inferir que as organizações, independente de terem ou não finalidades lucrativas, são organismos vivos, compostas por vários sistemas complexos, que permeiam tanto a estruturação formal (hierarquia e divisão de departamentos) quanto as relações estabelecidas entre os funcionários e destes com o macro-ambiente externo à organização. Sendo assim, considerando que a valoração do sujeito enquanto ser subjetivo e multifacetado é um dos pilares basilar da referida teoria, torna-se de fundamental importância que a GI e a GC partam da premissa complexa.

Considerando que o conhecimento pode ser tido como uma espécie de tradução efetuada pelo sujeito das realidades (objetos) do mundo exterior, e que sujeito e objeto não são entidades separadas - uma vez que o primeiro só cria conhecimento a partir do momento em que assume o compromisso de estabelecer um "auto-envolvimento" com o objeto (Nonaka e Takeuchi, 2008) -, é possível afirmar que o conhecimento, a partir dessa perspectiva interpretativa, finca suas bases na dimensão ontológica do ser. A consequência direta dessa premissa é que as empresas que desejam ampliar o conhecimento só conseguem fazê-lo a partir dos seus sujeitos organizacionais, criando maneiras de incentivá-los a compartilharem o conhecimento que detêm, de modo que a aprendizagem seja disseminada entre os grupos, organização e ambientes externos à mesma (Nonaka e Takeuchi, 2008). Portanto, é a partir das ações individuais que a rede de conhecimentos da organização é construída.

No que se refere à GI, a valoração do sujeito está presente em todos os modelos descritos no escopo desta pesquisa, onde a primeira etapa da GI correspondem à identificação das necessidades informacionais dos sujeitos que compõem as organizações, ainda que haja variações terminológicas.

Tendo em mente que o pensamento complexo se caracteriza por ser sistêmico, é necessário que as relações estabelecidas entre os conceitos sejam conjuntivas ao invés de disjuntivas. Quando se aplica essa lógica de soma na reflexão das relações entre gestão da informação e do conhecimento, ambas compostas por processos, é necessário levar em conta a relação de condicionalidade estabelecida entre as mesmas, pois enquanto a informação é condicionante do conhecimento, este último só pode ser construído por meio da ressignificação da informação pelo sujeito, ou seja, a informação tanto condiciona quanto é condicionada pelo conhecimento, fazendo com que a avaliação das necessidades de informação, etapa inicial da GI, tenham consequências diretas na GC. Nas palavras de Souza, Dias e Nassif (2011, p. 60):

Da mesma forma que o conhecimento se coloca em uma escala qualitativamente superior à informação, a gestão do conhecimento se localiza em um estágio posterior a gestão da informação. Contudo, esta corresponde a um dos condicionantes daquela, na mesma perspectiva que a gestão dos recursos informacionais compõe às estruturas da gestão da informação.

Portanto, a relação de condicionalidade entre GI e GC tem que necessariamente ser levada em conta para que ambas possam oferecer benefícios enquanto vantagens competitivas para as organizações, não podendo uma ser aplicada sem levar em conta a outra.

Essa mesma relação de condicionalidade não pode ser abordada de forma independente do contexto em que ocorre, isto é, a cultura organizacional e as práticas organizacionais, que de acordo com Souza, Dias e Nassif (2011) são consideradas, respectivamente, como os níveis operacional, contextual e operacional da gestão da informação e do conhecimento. Isso implica que tanto a cultura quanto as práticas organizacionais devem ser favoráveis aos sistemas complexos correspondentes às gestões, implicando necessariamente em um ambiente favorável à troca, uma vez que de acordo com Morin (2005, p. 274), “A alta complexidade está ligada ao desenvolvimento das comunicações, das trocas econômicas e de ideias, ao jogo dos antagonismos entre interesses, paixões e opiniões". 
Dessa forma, para verificar se de fato a empresa pesquisada possui práticas de GI e GC voltadas ao pensamento complexo, optou-se pela metodologia Análise de Conteúdo para a realização e análise de resultados da pesquisa empírica.

\section{Metodologia}

Realizou-se uma pesquisa descritivo-exploratória de natureza qualitativa, com o intuito de analisar se uma empresa do setor de comunicação e tecnologia apresenta fatores que indicam uma cultura organizacional voltada à promoção e desenvolvimento da gestão da informação e do conhecimento em suas práticas de trabalho, com base na teoria da complexidade.

A empresa pesquisada é dotada de 12 funcionários, dentre eles: programadores, analistas de sistemas, redatores, profissionais de marketing e publicidade e propaganda, administradores, entre outros, que têm por objetivo prestar serviços de consultoria empresarial e em paralelo desenvolver serviços de comunicação e tecnologia às empresas de diversos segmentos de mercado.

De acordo com Marconi e Lakatos (2013), os estudos descritivo-exploratórios possuem o objetivo de descrever completamente determinado fenômeno. Como instrumento de coleta de dados optou-se pelo roteiro de entrevista, e para análise dos dados, empregou-se o método de análise de conteúdo de Bardin (2009), utilizando-se a técnica de análise categorial.

Torna-se importante enfatizar que as entrevistas foram realizadas e gravadas em áudio na empresa em xeque, localizada na cidade de Bauru, na região centro-oeste do estado de São Paulo, Brasil, entre os dias 11/12/2017 e 12/12/2017, sendo realizadas com os seguintes colaboradores: programador back-end, programador front-end, programador full stack, assistente administrativa, designer e redatores. Além disso, cada entrevista teve duração média de 8 minutos.

Para Marconi e Lakatos (2013), a entrevista é um instrumento de coleta de dados que oferece maior flexibilidade no esclarecimento das perguntas, além de oferecer mais oportunidade para avaliar as atitudes e veracidade das respostas, visto que as atitudes e os gestos do entrevistado estão sendo observados.

A técnica de análise de conteúdo de Bardin (2009, p. 44) é considerada

um conjunto de técnicas de análise das comunicações visando obter, por procedimentos, sistemáticos e objetivos de descrição do conteúdo das mensagens, indicadores (quantitativos ou não) que permitam a inferência de conhecimentos relativos às condições de produção/recepção (variáveis inferidas) destas mensagens.

As categorias para a análise dos dados coletados (Tabela 1) foram definidas a posteriori, e elaboradas a partir das Atividades base de Gestão do Conhecimento e Atividades base da Gestão da Informação de Valentim (2004) e dos sete princípios da complexidade de Morin (2013), que por sua vez, também fundamentaram a elaboração das entrevistas. 
TABELA 1.

Categorias e Inferências para Análise de Dados

\begin{tabular}{|c|c|}
\hline Categorias & Inferências \\
\hline \multirow{3}{*}{$\begin{array}{l}1^{9} \text { Categoria: Identificação da necessidade de } \\
\text { informação (Princípio Hologramático); } \\
\text { (Princípio da auto-eco-organização). }\end{array}$} & O que considera informação. \\
\hline & $\begin{array}{l}\text { Como identifica o tipo de informação } \\
\text { necessária. }\end{array}$ \\
\hline & $\begin{array}{l}\text { Formas de obtenção da informação } \\
\text { necessária. }\end{array}$ \\
\hline \multirow{3}{*}{$\begin{array}{l}2^{\circ} \text { Categoria: Compartilhamento da } \\
\text { Informação (Princípio sistêmico ou } \\
\text { organizacional); (Princípio do círculo } \\
\text { retroativo); (Princípio dialógico); (Princípio do } \\
\text { círculo recursivo). }\end{array}$} & $\begin{array}{l}\text { Realização do compartilhamento da } \\
\text { informação entre os funcionários de todos os } \\
\text { setores. }\end{array}$ \\
\hline & $\begin{array}{l}\text { Existência de práticas de incentivo ao } \\
\text { compartilhamento da informação e expressão } \\
\text { opinativa dos funcionários. }\end{array}$ \\
\hline & $\begin{array}{l}\text { Existência da comunicação informal entre os } \\
\text { setores utilizando as TIC/Acesso à informação } \\
\text { de outros setores. }\end{array}$ \\
\hline \multirow{3}{*}{$\begin{array}{l}3^{\circ} \text { Categoria: Identificação da necessidade de } \\
\text { conhecimento (Princípio Hologramático); } \\
\text { (Princípio da auto-eco-organização). }\end{array}$} & O que considera conhecimento. \\
\hline & $\begin{array}{l}\text { Como identifica o tipo de conhecimento } \\
\text { necessário. }\end{array}$ \\
\hline & $\begin{array}{l}\text { Formas de obtenção do conhecimento } \\
\text { necessário. }\end{array}$ \\
\hline \multirow{3}{*}{$\begin{array}{l}4^{\circ} \text { Categoria: Compartilhamento do } \\
\text { conhecimento (Princípio sistêmico ou } \\
\text { organizacional); (Princípio do círculo } \\
\text { retroativo); (Princípio da reintrodução do } \\
\text { conhecimento em todo conhecimento); } \\
\text { (Princípio dialógico); (Princípio do círculo } \\
\text { recursivo). }\end{array}$} & $\begin{array}{l}\text { Realização do compartilhamento do } \\
\text { conhecimento entre os funcionários de todos } \\
\text { os setores. }\end{array}$ \\
\hline & $\begin{array}{l}\text { Existência de práticas de incentivo ao } \\
\text { compartilhamento do conhecimento dos } \\
\text { funcionários. }\end{array}$ \\
\hline & Acesso ao conhecimento de outros setores. \\
\hline
\end{tabular}

Fuente: Elaborado pelos autores.

Com as categorias e inferências estabelecidas, será exposto a seguir os resultados e as discussões perante a aplicação da entrevista, propondo uma relação entre as práticas da Gestão da informação e do conhecimento e teoria da complexidade.

\section{Resultados e Discussões}

Esclarece-se que o tratamento das informações coletadas foi organizado e estritamente baseado no método de análise de conteúdo de Bardin (2009), que esclarece ser esse um método de análise que proporciona aos 
pesquisadores o poder de inferência de conhecimentos relativos às mensagens adquiridas pelo instrumento de coleta de dados, fundamentado em indicadores e variáveis.

Para análise dos dados coletados foram utilizadas 4 categorias com 3 inferências para cada uma delas. As duas primeiras categorias estão relacionadas à GI, e as outras duas com a GC, sendo que ambas estão baseadas e inter-relacionadas com os sete princípios do pensamento complexo de Morin (2000). Assim, por meio dessas categorias foi possível interpretar o máximo de informaçóes pertinentes coletadas pelas entrevistas.

A primeira categoria é sobre identificação da necessidade de informação, relacionada com o Princípio hologramático e Princípio da auto-eco-organização. Essa categoria analisa o que os funcionários consideram como informação, como identificam o tipo de informação necessária no dia a dia de trabalho, e quais são as maneiras que eles obtêm as informações que consideram necessárias.

Com relação à primeira inferência, notou-se que muitos dos entrevistados possuem um conceito diferente de informação, mas que, de certa forma, esses conceitos se complementam. A informação foi definida, de maneira geral, como: (a) um saber inovativo, ou seja, um saber que só pode ser considerado informação se for uma novidade; (b) pedaços de coisas que se tem acesso por meio de pessoas ou internet; (c) tudo aquilo que você consegue captar em um ambiente e explicar; (d) uma espécie de etapa anterior ao conhecimento, que existe para auxiliar na construção do conhecimento e dos saberes; (e) elementos que se adquirem para um fim, para uso em alguma tarefa e (f) dados que podem ser transmitidos por algo ou por alguém.

A segunda inferência demonstrou que os funcionários identificam os tipos de informação que necessitam no momento em que vão realizar alguma tarefa, ou no próprio desenvolvimento dela. Para a maioria, os tipos de informação necessários variam muito, porque suas tarefas são muito dinâmicas, não são repetitivas, e por isso quase que diariamente lidam com problemas e tomadas de decisões diferentes que acabam exigindo tipos de informações também diferentes. E quando perguntados sobre as formas que utilizam para obter as informações que consideram necessárias, mais da metade respondeu que buscam perguntando aos seus superiores, ou para algum colega que tenha a informação desejada, e que, caso não obtenham sucesso nessas formas, fazem pesquisas na internet. Quanto ao restante, essa ordem de busca é o inverso.

As respostas dessa categoria foram ao encontro do princípio hologramático, que evidencia que as partes distintas e desintegradas podem ser vistas como um todo unido. E esse princípio foi representado nas diferentes respostas dos funcionários relativas aos conceitos de informação, que foram desintegrados, mas que se relacionaram podendo formar um só conceito mais abrangente.

O princípio da auto-eco-organização, que expressa a independência do ser humano e sua necessidade de se superar e de enfrentar os problemas encontrados foi evidenciado na forma que os funcionários identificam o tipo de informação que necessitam e na maneira que esses fazem para obtê-las, sempre com o foco de tomarem suas decisões e solucionarem seus problemas buscando essas informações em bases digitais ou humanas.

A $2^{\text {a }}$ categoria "Compartilhamento da Informação", relacionada ao princípio sistêmico ou organizacional, princípio do círculo retroativo, princípio dialógico e princípio do círculo recursivo buscou analisar se existe o compartilhamento da informação entre os setores da empresa; se existem práticas de incentivo ao compartilhamento da informação e a expressão de opinióes dos funcionários; se esses se comunicam de maneira informal utilizando as TIC, e se possuem acesso à informação de outros setores.

Foi possível perceber que a empresa se configura em um ambiente onde o compartilhamento da informação acontece de maneira frequente, pois praticamente todos os funcionários responderam que frequentemente compartilham informação com seus colegas e que também costumam tirar dúvidas com eles. Segundo os respondentes essa sinergia de compartilhamento se dá pela liberdade que possuem para tirarem pausas para um café e uma conversa, e também pela prática de uma reunião diária - criada por um dos gestores - onde todos os setores se unem em uma sala e falam sobre seus projetos, tarefas que estão sendo desenvolvidas, dúvidas que possuem, etc. A maioria acredita que essa reunião dá abertura para que os funcionários expressem suas opiniões, todavia, um dos entrevistados declarou que a reunião pode ser considerada mais um boletim sobre o que os setores andam fazendo, do que propriamente um ambiente propício e estimulante para os 
funcionários expressarem suas opiniões. Além disso, constatou-se que todos os setores se comunicam de maneira informal utilizando as TIC, como Facebook, Whatsapp, e-mail e Slack, e que o nível de acesso às informações de outros setores, pode ser considerado relativamente baixo.

Quanto à relação aos princípios do pensamento complexo, essa categoria se relacionou ao princípio sistêmico ou organizacional que declara ser improvável conhecer o todo sem conhecer as partes, e conhecer as partes sem conhecer o todo, mas que, ao mesmo tempo, o todo é mais do que a soma das partes. Nesse caso, como o nível de acesso dos funcionários de um setor aos outros setores é baixo, esse princípio não está sendo tão desenvolvido na empresa, mas ao mesmo tempo, caminha para ser desenvolvido com eficácia, ao passo que foi percebido que existe compartilhamento de informações entre os funcionários e comunicação informal utilizando as TIC. Nesse cenário, quanto mais os setores estiverem integrados, mais esse princípio estará sendo aplicado.

O princípio do círculo retroativo, que está ligado à situação de causa e efeito, foi relacionado ao ato de compartilhar e concomitantemente tirar dúvidas com os colegas, pois se hoje um funcionário compartilha uma informação, amanhã as chances de alguém compartilhar outra informação com ele são muito maiores, e assim cria-se uma sinergia relacionada à troca de favores. Outra questão que foi relacionada à evolução desse princípio na empresa foi o fato de que o que pode estar incitando a cultura do compartilhamento de informações que existe na empresa é a própria reunião diária que reúne os funcionários de todos os setores.

O fato dos funcionários de um setor não terem tanto acesso às informações de outros setores pode até ser visto como negativo quando se quer uma empresa totalmente integrada. No entanto, essa situação também pode ser positiva, pois estimula os gestores na construção de novas práticas que vão incentivar essa maior integração, e isso vai ao encontro com o princípio dialógico, que afirma que os elementos antagônicos podem ser complementares, e que a ordem e a desordem não são excludentes.

Por fim, constatou-se que o fato dos funcionários responderem com estima que o ambiente em que trabalham é dotado de muito compartilhamento e comunicação informal, demonstra que existe uma cultura do compartilhamento da informação na empresa. Além disso, o fato de um sujeito organizacional expor que as reuniões diárias necessitam de mais profundidade quanto ao ato de estimulá-los a expressarem suas opiniões demonstra que essa cultura está sendo construída pelos próprios funcionários, que adotaram a medida inicial dos gestores. E essa constatação se relaciona inteiramente ao princípio do círculo recursivo, no qual os indivíduos produzem a cultura de um ambiente, e também são resultados dessa cultura.

Como já foi dito no texto, as duas últimas categorias estão relacionadas à GC, portanto, a $3^{a}$ categoria é sobre identificação da necessidade de conhecimento, e está relacionada com o princípio hologramático e com o princípio da auto-eco-organização. Essa categoria pretende analisar o que os funcionários consideram como conhecimento, como identificam o tipo de conhecimento necessário no trabalho, e quais são as formas de obter o conhecimento que consideram necessário.

Foi percebido que o conceito de conhecimento expresso pelos funcionários esteve muito relacionado à informação e ao aprendizado, pois para a grande maioria ele é um acumulo de informações que foi enraizado dentro de cada um; são informações aprendidas por meio da prática. Quanto à segunda inferência, relativa à identificação dos tipos de conhecimentos necessários, os funcionários responderam basicamente o mesmo quando perguntado sobre o conceito de informação. Assim, os funcionários identificam os tipos de conhecimento de acordo com as tarefas que vão realizar, ou algum problema que surge no decorrer da tarefa, além disso, pôde-se perceber que tratam conhecimento como informação, no momento em que praticamente todos responderam que conseguem obtê-lo por meio da internet ou dos outros colegas de trabalho.

Nesta categoria, o princípio hologramático não segue com profundidade no contexto organizacional, pois as respostas dos funcionários quanto ao conceito de conhecimento foram muito uniformes. E quanto ao princípio da auto-eco-organização, o mesmo permanece como na $1^{\text {a }}$ categoria, voltado à informação, onde os funcionários de alguma forma buscam solucionar seus problemas e tomarem suas decisões pela busca do conhecimento. 
A $4^{\text {a }}$ categoria - referente ao compartilhamento do conhecimento, e relacionada ao Princípio sistêmico ou organizacional, Princípio do círculo retroativo, Princípio da reintrodução do conhecimento em todo conhecimento, Princípio dialógico e Princípio do círculo recursivo - procurou analisar se existe compartilhamento do conhecimento entre os setores da empresa, se há práticas de incentivo ao compartilhamento e se os funcionários possuem acesso ao conhecimento de outros setores.

Foi possível identificar que existe a prática do compartilhamento do conhecimento, porém os funcionários deixaram bem claro que esse compartilhamento acontece em um círculo mais fechado de setores, por exemplo, os funcionários do setor de redação compartilham seus conhecimentos mais com os funcionários do mesmo setor; o mesmo acontece com os outros setores.

Quanto à existência de práticas de incentivo ao compartilhamento do conhecimento, os funcionários alegaram não ter, pois para eles, as práticas são mais voltadas ao compartilhamento de informações do que propriamente de conhecimento. E o mesmo acontece com o nível de acesso ao conhecimento de outros setores, onde alguns declaram não ter acesso aos outros setores por falta de interesse, e outros por falta de tempo e/ou intimidade.

Dessa maneira, como o nível de acesso ao conhecimento dos funcionários de um setor aos outros setores é muito baixo, o princípio sistêmico ou organizacional não está sendo aplicado com efetividade na empresa, mas ao mesmo tempo, como na $2^{\text {a }}$ categoria, caminha para ser desenvolvido com eficácia, pois se percebeu que existe compartilhamento de conhecimento entre os funcionários.

Esta categoria também se relacionou com o princípio da reintrodução do conhecimento em todo conhecimento, que incentiva a construção desse ativo por meio de outros ativos e que preza pela inovação, porque a existência do compartilhamento de conhecimentos entre os funcionários demonstra que o ambiente organizacional busca construir conhecimento por meio da interação entre os seus funcionários, mesmo que os setores ainda não estejam tão interligados.

De uma maneira geral, as constatações relativas aos demais princípios: do círculo retroativo, dialógico e do círculo recursivo foram basicamente as mesmas reiteradas na $2^{\mathrm{a}}$ categoria, porém estritamente voltadas ao objeto do conhecimento.

\section{ConClusões}

Por meio desta pesquisa buscou-se verificar se uma empresa do setor de comunicação e tecnologia apresenta fatores que indicam uma cultura organizacional voltada à promoção e ao desenvolvimento da gestão da informação e do conhecimento em suas práticas de trabalho, com base na teoria da complexidade.

Foi feita uma análise de conteúdo das respostas coletadas na entrevista através de algumas categorias e inferências, onde constatou-se que o ambiente organizacional desenvolve de maneira mais acentuada as práticas de GI do que de GC, baseando-se em alguns princípios do pensamento complexo desenvolvidos em paralelo com a GI.

Concomitantemente, foi percebido que o ambiente da empresa possui características de comunicação informal e que as bases de informação humanas são bem valorizadas pelos funcionários, além do mais, os mesmos demonstram gostar muito desse ambiente de compartilhamento e até mesmo expressam ideias de melhorias nas práticas de expressão dos funcionários e interação com os demais setores. Afinal, também foi percebido que os setores não são integrados, e que o compartilhamento de informações acontece mais entre os funcionários pertencentes ao mesmo setor.

A GC ainda não parece ser tão desenvolvida na empresa, pois percebe-se que mesmo que os funcionários saibam da diferença entre informação e conhecimento, acabam confundindo ambas e tendo conhecimento como a própria informação. Porém, as culturas do compartilhamento da informação e as reuniões que são desenvolvidas diariamente já podem ser consideradas a prática inicial para o desenvolvimento de uma cultura 
voltada à GC no ambiente organizacional, assim, declara-se que a empresa caminha para esse processo, pois tem a cultura da GI bem enraizada.

Quanto ao desenvolvimento do pensamento complexo nas práticas de trabalho da empresa, notou-se que dos sete princípios do pensamento complexo, os únicos que estão sendo desenvolvidos, de maneira indireta, na empresa são: princípio hologramático, princípio da auto-eco-organização, princípio do círculo retroativo e princípio do círculo recursivo, o que configura mais da metade, portanto, um resultado satisfatório, se levar em consideração o nível de consistência da sociedade da informação e do conhecimento nos tempos atuais.

Ademais, pôde-se constatar que a GI e a GC são processos que estão muito relacionados com a teoria da complexidade, e, portanto, com o futuro pós-moderno da sociedade da informação e do conhecimento.

Como limitações da pesquisa, pode-se dizer que houve certo receio em relacionar assuntos robustos e subjetivos como a gestão da informação e do conhecimento e a teoria da complexidade, porém, essa limitação foi, de certa forma, o fator estimulador para o desenvolvimento da pesquisa, pois os autores acreditam que a ciência cresce de acordo com o grau de inovação e ousadia dos pesquisadores.

Dessa maneira, indicam-se também futuras investigações que façam essa mesma análise em outros segmentos empresariais, a fim de estimular o desenvolvimento do pensamento complexo e da gestão da informação e do conhecimento nas organizações contemporâneas, com o intuito de fortalecer a atual sociedade.

\section{REFERÊNCIAS}

Bardin, L. (2009). Análise de conteúdo (4a ed.). Lisboa: Edições 70.

Cascão, F. (2014). Gestão de competências, de conhecimento e de talento: estudos e contributos para a gestão das pessoas no séc. XXI. Edições Sílabo.

Choo, C. W. (2003a). A organização do conhecimento: como as organizaçôes usam a informação para criar significado, construir conhecimento e tomar decisões. São Paulo: Senac.

Choo, C. W. (2003b). Gestão de informação para a organização inteligente: a arte de explorar o meio ambiente. Lisboa: Caminho.

Davenport, T. H. (1994). Reengenharia de processos. São Paulo: Campus.

Davenport, T. H. (2002). Ecologia da Informação. São Paulo: Futura.

Davenport, T. H., e Prusak, L. (1998). Conhecimento empresarial: como as organizaçóes gerenciam o seu capital intelectual. Rio de Janeiro: Campus.

Geertz, C. (2013). O Saber Local: novos ensaios em antropologia interpretativa (12a ed.). Petrópolis: Vozes.

Heisig, P., Suraj, A. O., Kianto, A., Kemboi, C., Arrau, G. P., e Easa, N. F. (2016). Knowledge management and business performance: global experts' views on future research needs. Journal of Knowledge Management, 20(6), 1669-1198. https://doi.org/10.1108/JKM-12-2015-0521

Madsen, D. (2013). Disciplinary perspectives on information management. Em The 2nd International Conference on Integrated Information. Procedia: social and behavioral sciences, 73.

Malin, A. M. B. (2012). O campo profissional da Gestão da Informação. Informação \& Informação, 17(2), 172-187. h ttp://dx.doi.org/10.5433/1981-8920.2012v17n2p172

Marconi, M. A., e Lakatos, E. M. (2013). Fundamentos de metodologia cientifica. São Paulo: Atlas.

Martins, S. C. (2014). Gestão da Informação: estudo comparativo de modelos sob a ótica integrativa dos recursos de informação. (Dissertação de mestrado em Ciência da Informação), Universidade Estadual Paulista, Faculdade de Filosofia e Ciências, Marília, São Paulo, Brasil.

Mead, M., Benedict, R., Sapir, E., e Borges, M. A. X. de. A. (2015). Cultura e Personalidade. Rio de Janeiro: Zahar.

McGee, J., e Prusak, L. (1994). Gerenciamento estratégico da informação. Rio de Janeiro: Campus.

Morin, E. (2000). A cabeça bem-feita: repensar a reforma, reformar o pensamento. Rio de Janeiro: Bertrand Brasil. 
Morin, E. (2005). Os sete saberes necessários à educação do futuro. São Paulo: Cortez.

Morin, E. (2007). Introdução ao pensamento complexo. Porto Alegre: Sulina. [Tradução de Eliane Lisboa].

Morin, E. (2013). Ciência e consciência da complexidade. Em E. Morin e J. Le Moigne (Org.), A inteligência da complexidade. São Paulo: Peirópolis.

Nonaka, I., e Takeuchi, H. (2008). Teoria da criação do conhecimento organizacional. Em H. Takeuchi e I. Nonaka (Org.), Gestão do conhecimento. Porto Alegre: Bookman.

Ponjuán Dante, G. (2007). Gestión de información: dimensiones e implementación para el êxito organizacional. Gijón: Trea.

Ronchi, C. C. (2012). Cultura e as organizaçôes: antropologia e cultura brasileira. Curitiba: Juruá.

Schein, E. H. (2009). Cultura organizacional e liderança. São Paulo: Atlas.

Silva, T. E., e Tomaél, M. I. (2007). A gestão da informação nas organizações. Informação \& Informação, 12(2), 1-2. h ttp://dx.doi.org/10.5433/1981-8920.2007v12n2p148

Souza, E. D. de., Dias, E. J. W., e Nassif, M. E. (2011). Gestão da informação e do conhecimento na Ciência da Informação: perspectivas teóricas e práticas organizacionais. Informação e Sociedade: Estudos, 21(1), 55-70. Recuperado de http://www.brapci.inf.br/index.php/article/download/16973

Valle, R., e Costa, M. M (2013). Gerenciar os processos, para agregar valor a organização. Em R. Valle e S. B. de Oliveira (Org.). Análise e modelagem de processos de negócio: foco na notação BPMN (Business Process Modeling Notation). São Paulo: Atlas.

Valentim, M. L. P. (2004). Gestão da informação e gestão do conbecimento: especificidades e convergências. Recuperado de http://www.ofaj.com.com/colunas_conteudo.php?cod=88.

Valentim, M. L. P. (2007). Informação, conhecimento e inteligência organizacional (2a ed.). Marília: Fundepe.

Valentim, M. L. P. (2010). Gestão, Mediação e Uso da Informação. São Paulo: Cultura Acadêmica. 